(C) 2014 IEEE. Personal use of this material is permitted. Permission from IEEE must be obtained for all other uses, in any current or future media, including reprinting/republishing this material for advertising or promotional purposes, creating new collective works, for resale or redistribution to servers or lists, or reuse of any copyrighted component of this work in other works.

This is the Author's Accepted Manuscript version of a paper published in the proceedings of the 2014 IEEE International Conference on Industrial Engineering and Engineering Management in December 2014.

The full citation of the original IEEE publication is:

Adebanjo, D., Tickle, M., Ojadi, F., leromonachou, P., Laosirihongthong, T. and Michaelides, R. (2014) Supplier selection activities in the service sector: A case study in Nigeria. In: 2014 IEEE International Conference on Industrial Engineering and Engineering Management. Institute of Electrical and Electronics Engineers, Inc., Piscataway, NJ, USA, pp. 189-193. ISBN 9781479964109 (doi:10.1109/IEEM.2014.7058626)

The final publication is available at IEEE via http://dx.doi.org/10.1109/IEEM.2014.7058626 


\section{Supplier Selection Activities in the Service Sector: A Case Study in Nigeria}

D. Adebanjo ${ }^{1}$, M. Tickle ${ }^{2}$, F. Ojadi ${ }^{3}$, P. Ieromonachou ${ }^{1}$, T. Laosirihongthong ${ }^{4}$, R.Michaelides $^{2}$

${ }^{1}$ Management and Logistics, University of Greenwich, London, United Kingdom (D.Adebanjo@greenwich.ac.uk)

${ }^{2}$ Operations Management Group, University of Liverpool, Liverpool, United Kingdom (mtickle@ liv.ac.uk; roulam@liv.ac.uk)

${ }^{3}$ Operations Management Group, University of Lagos, Lagos, Nigeria (fojadi@lbs.edu.ng)

${ }^{4}$ Department of Industrial Engineering, Faculty of Engineering, Thammasat University, Pathumtanee, Thailand (ltritos@engr.tu.ac.th)

\begin{abstract}
This paper presents the results of the supplier selection process conducted by a Nigerian service sector organization. One organization was used as a case study whereby data collection involved an action research approach; the data was then subject to statistical analysis via the SPSS Statistics software package. In total, 185 potential suppliers were assessed. Several statistically significant differences were also found between those suppliers that met the minimum requirements and those that did not as well as between organizations that offered products and organizations that offered services.
\end{abstract}

Keywords - Nigeria, Purchasing, Supplier selection

\section{INTRODUCTION}

In order to achieve supply chain success, organizations must successfully manage the relationships they have with their suppliers [1, 2]. Today's organizations realize that the performance of their suppliers can have a huge impact on their own performance [3] and so take great steps to ensure that they choose the right supplier from the get go.

This paper reports the results of a supplier selection process for minor (low cost/value) products and services within a large Nigerian service organization that has over 200 offices nationwide. The motivation for the study was based on 2 distinct factors; firstly, the rapid growth of the service sector and the increased academic interest in service supply chains [4-6]. Secondly, the relative lack of studies on supply chain management in Nigeria and the suggestion that procurement activities in developing economy organizations lag those in their developed counterparts [7]. This focus on Nigeria is particularly important due to the country having the largest population in Africa (160 million). The study identifies numerous different categories of products and services and then evaluates the ability of numerous supplier organizations to fulfill the requirements of the case study company

In today's global environment, the success of an organization often depends on their ability to build a network of reliable suppliers thereby indicating that supplier selection decisions are highly important [8]. The vast majority of research conducted on supplier selection activities is studied within the manufacturing industry [9, 10] possibly due to the impact of the costs of raw materials on the final assembled product [11].

Several previous studies have concentrated on the criteria for selecting reliable suppliers; some have focused on quality [12], others on risk [13], whilst others have concentrated on cost and service levels [14]. One study
[15] suggested that management capability, culture, communication and technical ability are all important criteria in the supplier selection process, whereas another study [16] suggest looking at capability factors and performance factors.

Service sector organizations do not sell physical products. However their supplier selection typically applies to purchase of maintenance, repair and operations (MRO) inventory which can have a significant impact on the day-to-day running of the organization; successful MRO inventory can lead to improved productivity, reduced cost and better inventory management [17]. MRO inventory can include office supplies, computer equipment and repair parts and account for a significant proportion of organizational cost given the large number of transactions of low value items [18].

When wishing to optimize the supplier selection process, a ranking approach is normally adopted; five types of ranking approaches were identified by [16] which include linear weighting models; total cost of ownership models; mathematical programming models; statistical models; and, artificial intelligence based models. The case study organization in this research utilized a linear weighting model; this model assigns weights to selection criteria and the most important criteria are given the largest weightings.

\section{A. Background to Nigeria}

The most populated country in Africa (160 million), Nigeria also has one of the 3 largest economies in the African continent with a GDP of US\$193.6bn [19]. This GDP places Nigeria as the $44^{\text {th }}$ in the world and $31^{\text {st }}$ in the world in terms of purchasing power parity [19].

Crop production remains the most active sector with regard to contribution to GDP whilst the wholesale and retail trade sector, crude petroleum and natural gas and the telecommunications sector are all growing sectors. The Nigerian market is controlled by a small number of large organizations who currently hold the bulk of the power within the supply chain.

\section{B. The case study company}

The case study company for this research is one of the major service providers with over 200 offices across Nigeria. It has over 1,500 employees across all functions and states that maintenance, repair and operations (MRO) inventory is of the highest importance to the effective running of the organization's various offices. Previously, the company had adopted a localized approach to 
procurement, where each location took responsibility for purchasing their own products and services. A small number of senior managers therefore had the responsibility of supplier selection and the process therefore lacked transparency and objectivity. Subsequently, the supplier selection process varied dramatically across the organization, as did the prices for identical products and services.

As a result of this, the case study company has made substantial changes to its policies and processes. The purchasing process was given particular attention with a view to standardizing the process. Subsequently, a nationwide exercise was conducted to identify and evaluate potential suppliers based on set criteria; with this goal in mind, a list of preferred suppliers that met the minimum set of standards required was drawn up.

\section{Objectives of the Research}

The research has three major objectives as follows:

Objective 1: To explore if organisations in developing countries need to identify and select criteria that complement their values and enable discrimination between potential suppliers.

Objective 2: To explore if in order to become competitive in the provision of goods and services to prized customers in developing countries, suppliers would need to develop new practices and competencies that they may otherwise, have failed to adopt.

Objective 3: To explore if the organisational values of customer organisations, has the potential to be reflected on their supplier base and consequently shape business culture in countries where regulatory frameworks may be unable to do so.

\section{METHODOLOGY}

The case study method was adopted for this study due to the multiple insights the method offers from numerous different angles [20]. Case studies also support both qualitative and quantitative data collection and analysis and, as a result, offer a great depth of analysis to be conducted [21]. Reference [22] suggests that this particular study utilized a single case approach due to the case itself being a representative and revelatory case; the case study organization is typical of those found in its sector and the products / services it procures are highly similar to those its competition would procure.

In terms of data collection, the action research approach was adopted which is "...the application of factfinding to practical problem-solving in a social situation with a view to improving the quality of action within it" [23]. One member of the research team was involved as a "participant as observer" to collect the data necessary for the study. Reference [23] states that action research is suitable for research that is situational, collaborative, participatory and self-evaluative; this study meets all of these criteria as have various other studies in operations management that have also utilized this approach [24, 25].
Data collection involved identifying 13 categories of minor spend products or services that the case study company procured on a regular basis. After this, a set of preferential criteria for potential suppliers was produced and a scoring matrix developed for each criteria area based on the criteria's importance to the case study company. An acceptable minimum score was also agreed for each criteria. Table I highlights the 13 categories whilst Table II shows the criteria and their associated weightings.

TABLE I

LIST OF ALL 13 CATEGORIES

\begin{tabular}{|l|l|}
\hline \multicolumn{1}{|c|}{ Category } & Product / Service \\
\hline Office Stationary and Provisions & Product \\
\hline Office Consumables & Product \\
\hline $\begin{array}{l}\text { Minor Electrical Services, Electrical Spares, } \\
\text { Lighting Arrestor }\end{array}$ & Service \\
\hline $\begin{array}{l}\text { Plumbing Materials and Minor Plumbing } \\
\text { Services }\end{array}$ & Service \\
\hline Sewage Disposal Services & Service \\
\hline Indoor, Outdoor and Other Gardening Services & Service \\
\hline Vehicle Maintenance Services & Service \\
\hline Office Waste Disposal Services & Service \\
\hline Fumigation and Pest Control Services & Service \\
\hline Specialist Services & Service \\
\hline Catering Services & Service \\
\hline Corporate Uniforms & Product \\
\hline Services for Telephones & Service \\
\hline
\end{tabular}

With the categories and supplier criteria identified, advertisements were placed in the major national newspapers that invited potential suppliers to submit company information as well as evidence to support their claim of meeting the specified criteria (e.g. certificates of accreditation, recent job references, training certificates etc.). A total of 185 responses were received, all of which were scored and ranked according to the criteria.

Once ranked, the data were analysed through use of the SPSS Statistics software package where parametric tests such as mean, standard deviation and t-tests were conducted, as suggested by [26] given the data were on a continuous scale and normally distributed.

TABLE II

LIST OF SUPPLIER CRITERIA AND THE ASSOCIATED WEIGHTINGS

\begin{tabular}{|c|c|c|}
\hline No. & \multicolumn{1}{|c|}{ Criteria } & Weighting \\
\hline \multirow{3}{*}{1} & Adequacy of legal and civic capabilities & $(30)$ \\
\cline { 2 - 3 } & a) Legal & 15 \\
\cline { 2 - 3 } 2 & $\begin{array}{l}\text { Adequacy of Firm's specific and General } \\
\text { experiences, resources and other capabilities }\end{array}$ & 15 \\
\hline \multirow{4}{*}{2.1} & $\begin{array}{l}\text { List of 3 recent job references carried out in the } \\
\text { past 3 years (with verifiable evidence) }\end{array}$ & $(70)$ \\
\cline { 2 - 3 } & I. 3 or more examples & 20 \\
\cline { 2 - 3 } & II. 2 examples & 10 \\
\cline { 2 - 3 } 2.2 & III. 1 example & 5 \\
\hline \multirow{4}{*}{} & $\begin{array}{l}\text { EH\&Q Capability with verifiable policy and } \\
\text { procedures }\end{array}$ & $(10)$ \\
\cline { 2 - 3 } & a) Quality policy and procedures & 3 \\
\cline { 2 - 3 } & b) Health and Safety policy and procedures \\
\hline
\end{tabular}




\begin{tabular}{|c|c|c|}
\hline & c) Workmanship Insurance & 4 \\
\hline \multirow{4}{*}{2.3} & $\begin{array}{l}\text { Service and Flexibility capabilities (with verifiable } \\
\text { evidence of locations and affiliations) }\end{array}$ & (40) \\
\cline { 2 - 3 } & $\begin{array}{l}\text { I. Coverage of 3 key locations (Lagos, PH, } \\
\text { Abuja) }\end{array}$ & 25 \\
\cline { 2 - 3 } & $\begin{array}{l}\text { II. Coverage of only 2 out of 3 key } \\
\text { locations }\end{array}$ & 10 \\
\cline { 2 - 3 } & III. Coverage of one key location & 5 \\
\cline { 2 - 3 } & a) Coverage of other locations & 10 \\
\cline { 2 - 3 } & b) OEM affiliations & 20 \\
\hline
\end{tabular}

\section{RESULTS}

Various t-tests were conducted to investigate several areas of interest, the results of which will now be discussed. The first independent samples t-test compared the performance differences between those organizations that had met the minimum acceptable performance and those that had not met the criteria. The results showed statistically significant differences between these two organization types in the areas of Adequacy of Civic Capabilities ( $\mathrm{p}<0.005, \mathrm{t}=-9.849)$, Examples of 3 Recent Jobs Carried Out in past 3 Years $(\mathrm{p}<0.005, \mathrm{t}=-5.5)$, Quality Policy and Procedures $(\mathrm{p}<0.05, \mathrm{t}=-2.512)$, Health and Safety Policy and Procedures $(\mathrm{p}<0.05, \mathrm{t}=-$ 2.589), Workmanship Insurance $(p<0.005, t=-4.080)$, Service and Flexibility Capabilities $(\mathrm{p}<0.005, \mathrm{t}=$ 4.294), Coverage of Other Locations ( $p<0.05, t=-$ 2.702), OEM Affiliations ( $\mathrm{p}<0.005, \mathrm{t}=-3.376)$ and Total Score $(\mathrm{p}<0.005, \mathrm{t}=-11.777)$. This finding suggests that those organizations that met the criteria performed better than their counterparts in these areas.

The second t-test looked at investigating the differences between those organizations offering a product and those offering a service. On average, service organizations outperformed their product-based counterparts in every category bar the Service and Flexibility Capabilities category where the means were very similar (product organizations $=10.48$; service organizations $=10.41$ ). The results also showed a number of statistically significant differences between the 2 types of organization in the areas of Adequacy of Civic Capabilities ( $p<0.05, t=-2.425)$, Examples of 3 Recent Jobs Carried Out in the past 3 years $(\mathrm{p}<0.005, \mathrm{t}=$ 3.104), Quality Policy and Procedures $(\mathrm{p}<0.05, \mathrm{t}=$ $2.204)$, Health and Safety Policy and Procedures ( $\mathrm{p}<$ $0.05, \mathrm{t}=-2.831)$, Workmanship Insurance $(\mathrm{p}<0.005, \mathrm{t}=-$ 4.532), Coverage of Other Locations ( $\mathrm{p}<0.05, \mathrm{t}=-$ $2.014)$, and Total Score $(\mathrm{p}<0.005, \mathrm{t}=-4.263)$. There were no statistically significant differences between product and service-based organizations in regards to Adequacy of Legal Capabilities $(\mathrm{p}=0.319, \mathrm{t}=-1.004)$, Service and Flexibility Capabilities (Evidence of Locations) $(\mathrm{p}=0.931, \mathrm{t}=0.087)$ or OEM Affiliations ( $\mathrm{p}=$ $0.473, t=-0.719)$. These findings indicate that service suppliers are more likely to provide evidence for their skills and experience, are more willing to provide services outside their key locations and are more likely to take better care of their employees (i.e. quality policy and procedures, health and safety policy procedures, and workmanship insurance). A possible explanation for this could be that, in general, the product suppliers in this study are not OEMs but rather intermediaries / traders that primarily purchase from OEMs to sell to organizations without adding any value; as such, they may not see that they need the various insurances and policies / procedures. The service organizations, in comparison, require a different skill set (certainly a more specialized one) especially when working in hazardous environments such as fumigation and pest control, sewage disposal and vehicle maintenance; they are therefore more likely to understand the importance of workmanship insurance, quality procedures and health and safety procedures.

The third t-test compared the results of product organizations that had met the minimum acceptable performance with those product organizations that had not met the minimum acceptable performance. There were statistically significant differences between the two organization types in the areas of Adequacy of Civic Capabilities ( $\mathrm{p}<0.005, \mathrm{t}=-5.026$ ), Examples of 3 Recent Jobs Carried Out in past 3 Years $(\mathrm{p}<0.005, \mathrm{t}=-4.196)$. This shows that although product suppliers lagged service suppliers in many areas of the criteria, it was more difficult to distinguish between the two types of product supplier.

Similar to the previous t-test, the fourth test investigated the differences between service organizations that met the minimum acceptable performance and service organizations that did not meet the minimum acceptable performance. These results were more conclusive; there were statistically significant differences in the areas of Adequacy of Civic Capabilities ( $\mathrm{p}<0.005, \mathrm{t}=-8.066$ ), Examples of 3 Recent Jobs Carried Out in past 3 Years ( $<0.005, \mathrm{t}=-3.648)$, Health and Safety Policy and Procedures $(\mathrm{p}<0.05, \mathrm{t}=-2.312)$, Workmanship Insurance $(\mathrm{p}<0.005, \mathrm{t}=-3.682)$, Service and Flexibility Capabilities (Evidence of Locations) $(\mathrm{p}<0.005, \mathrm{t}=-$ 3.833), Coverage of Other Locations $(\mathrm{p}<0.05, \mathrm{t}=-$ 2.306), OEM Affiliations ( $\mathrm{p}<0.005, \mathrm{t}=-3.826)$, and Total Score $(p<0.005, t=-9.918)$. This shows there is far greater variation between service organizations. A worrying finding was that a number of prospective suppliers for hazardous services could not provide sufficient evidence of recent jobs or had no health and safety procedures / insurance for their employees.

\section{DISCUSSION}

This study aimed to investigate the impact of a standardized supplier selection strategy on supplier performance. A total of 185 potential suppliers applied to be considered as new suppliers to the case study company; only a minority of these were legacy suppliers, of which some did not meet the minimum acceptable criteria in their categories.

The results show that almost all of the supplier organizations are registered with the government and can therefore legally conduct business in the categories they 
applied for. This is shown by the mean value of the Adequacy of Legal Capabilities score being 14.57 out of 15. This implies that almost all of the 185 supplier organizations could easily declare their accounts and pay taxes on an annual basis; however, the Adequacy of Civic Capabilities score averaged 9.11 out of 15 thereby suggesting that a significant majority of these organizations were unable to supply evidence that they had paid taxes.

Another finding was that scores for Quality Policy and Procedures, Health and Safety Policies and Procedures and Workmanship Insurance were generally poor. This is, however, not too surprising; there is currently no national framework to encourage and maintain the uptake of these criteria. Moreover, the products and services covered in this study are likely to be offered by small businesses who are rather unlikely to be motivated to implement these criteria by choice.

The overall implication of the study's findings is that supplier behavior and performance in Corporate Social Responsibility (CSR) practices was very poor; in fact the key differentiator between those that met the minimum performance criteria and those that did not was the adoption of these practices. In some respects this is not surprising; one study [27] found that a quarter of the 103 respondents in UK SME suppliers would be put off tendering for contracts should CSR requirements be included in the preconditions of the purchasing process.

\section{A. Products Vs. Services}

The results indicate that suppliers of services outperform suppliers of products in the areas of CSR and service flexibility. One suggestion for this could be the nature of services themselves; some of the work will be carried out in hazardous conditions (e.g. fumigation and pest control, electrical services, sewage disposal) and as such suppliers are more likely to adopt safety equipment, quality policies and insurance. It is also likely that service suppliers will keep better records of previous jobs due to insurance and maintenance reasons. Product suppliers, in contrast, are less likely to see a need for health and safety policies, quality policies and insurance.

\section{B. Key Contributions of the Study}

To discuss the key contributions of the study, we return to the objectives of this study. The fact that many legacy suppliers either failed to participate in the process or failed to achieve the minimum acceptable level of performance suggests that improvements have been made to the purchasing process as indicated in Objective 1 . While the use of supplier ranking systems as discussed by authors such [16] may be commonplace in developed economies, they may not be as widely adopted in developing economies and this study of a first time adoption by a major organisation in a developing country has shown significant weaknesses in the performance of most potential suppliers. The relatively small numbers of potential suppliers that achieved the minimum performance, therefore, suggests that in order to be competitive, others suppliers would need to adopt practices identified by their customers and which they might not have considered previously as indicated in Objective 2. This may concur with the observation by [1] that most suppliers only adopt CSR when it is required by customers. However [13] also suggested that some customer organisations may not have the clout to influence change in some of their suppliers. Within the context of this study, we believe that the requirements by ServiceOrg may have failed to influence most of their legacy suppliers to adopt new practices. Objective 3 explored the role and potential of customers to shape business culture in countries where regulatory frameworks are unable to do so. Institutional theory suggests that coercive, normative and mimetic pressures can all influence corporate behaviour. However, the fact that some of the potential suppliers analysed in this study were registered to pay tax but could not show evidence of doing so suggests that the regulatory framework that underpins coercive pressures in countries such as Nigeria may be weak. Based on the findings from this study, we suggest that there are significant differences between institutional pressures in developed and developing countries because of the highly established regulatory frameworks in developed countries in terms of factors such as health and safety, taxation, insurance, etc. We therefore conclude that for many factors in developed economies where coercive factors can play a dominant role in corporate behaviour, the weaker regulatory structures in developing countries implies that normative pressures, where deployed, have the potential to play a dominant role.

\section{CONCLUSION}

This study has shown the impact of supplier selection strategies on supplier performance. The results indicated a number of statistically significant differences between those suppliers that met the minimum performance requirements and those that did not as well as statistically significant differences between organizations that supply products and those that supply services.

An implication from this research is that coercive pressures should be used to encourage potential suppliers in developing countries such as Nigeria to embrace activities such as paying taxes and ensuring all employees are properly insured to conduct their jobs effectively. An interesting finding from this research was that many legacy suppliers decided not to participate in the selection exercise; this highlights the need for a formalized supplier selection process in countries and organizations where the selection process is informal and opaque.

In terms of industrial implications, this research has shown that organizations in developing countries should strongly consider adopting a formalized supplier selection strategy; adopting such a strategy will force organizations to consider the values and expectations important to them. 
Similarly, potential suppliers should amend their current practices to align them more accurately with the explicit requirements of their customers. This is particularly important if these customers are likely to move from localized supplier selection processes to a more transparent set of criteria as shown by the case study company in this study; in this scenario, those suppliers that continue using their inadequate processes will become locked out of their current (and future) markets. Finally, governmental organizations in developing nations need to realize that there are inadequacies in the behavior and performance of many of their organizations; as such there is a definite need for firm regulation and monitoring especially in the areas of tax receipts, health and safety and insurance certification.

\section{REFERENCES}

[1] M. Giannakis, "Facilitating learning and knowledge transfer through supplier development," Supply Chain Management: An International Journal, vol. 13, pp. 62-72, 2008.

[2] C. Sanchez-Rodriguez, D. Hemsworth, and A. Martinez-Lorente, "The effect of supplier development initiatives on purchasing performance: a structural model," Supply Chain Management: An International Journal, vol. 10, pp. 289-301, 2005.

[3] A. Carr, H. Kaynak, J. Hartley, and A. Ross, "Supplier dependence: impact on supplier's participation and performance," International Journal of Operations and Production Management, vol. 28, pp. 899-916, 2008.

[4] M. Caridi, R. Cigolini, M. Urciuoli, and A. Villa, "Reducing lead time in the banking industry: an experimental approach to the loan granting process," Production Planning \& Control, vol. 19, pp. 198-211, 2008.

[5] A. Fairchild, "Intelligent matching: integrating inefficiencies in the service supply chain," Supply Chain Management: An International Journal, vol. 10, pp. 244-248, 2005.

[6] B. Burnes and A. Anastadiasis, "Outsourcing: a public-private sector comparison," Supply Chain Management: An International Journal, vol. 8, pp. 355-366, 2003.

[7] K. Msimangria, "Purchasing and supply chain management practices in Botswana," Supply Chain Management: An International Journal, vol. 8, pp. 7$11,2003$.

[8] S. Matook, R. Lasch, and R. Tamaschke, "Supplier development with benchmarking as part of a comprehensive supplier risk management framework," International Journal of Operations and Production Management, vol. 29, pp. 241-267, 2009.

[9] M. Giannakis, "Management of service supply chains with a service-oriented reference model: the case of management consulting," Supply Chain Management: An International Journal, vol. 16, pp. 346-361, 2011.

[10] J. Field and L. Meile, "Supplier relations and supply chain performance in financial services processes," International Journal of Operations and Production Management, vol. 28, pp. 186-206, 2008.
[11] W. Ho, P. Dey, and M. Lockstrom, "Strategic sourcing: a combined QFD and AHP approach in manufacturing," Supply Chain Management: An International Journal, vol. 16, pp. 446-461, 2011.

[12] V. Lo and A. Yeung, "Managing quality effectively in supply chain: A preliminary study," Supply Chain Management: An International Journal, vol. 11, pp. 208-215, 2006.

[13] R. Levary, "Ranking foreign suppliers based on supply risk," Supply Chain Management: An International Journal, vol. 12, pp. 392-394, 2007.

[14] P. O'Brien, "Case Study: Vendor assessment for partners in supply," European Journal of Purchasing and Supply Management, vol. 1, pp. 49-59, 1998.

[15] K. Choi and W. Lee, "A generic supplier management tool for outsourcing manufacturing," Supply Chain Management: An International Journal, vol. 8, pp. 140-154, 2003.

[16] A. Sarkar and P. Mohapatra, "Evaluation of supplier capability and performance: A method for supply base reduction," Journal of Purchasing and Supply Management, vol. 12, 2006.

[17] G. Bailey and M. Helms, "MRO inventory reduction - challenges and management: a case study of the Tennessee Valley Authority," Production Planning and Control, vol. 18, pp. 261-270, 2007.

[18] Z. Michaelides, J. Ho, N. Boughton, and D. Kehoe, "The development and valuation of Internet-based supply of non-production (MRO) items," International Journal of Logistics Research and Applications, vol. 6, pp. 319-332, 2003.

[19] W. Bank. (2012, 02/03/2012). World Bank Development Indicators: Nigeria. Available: http://data.worldbank.org/country/nigeria

[20] G. Thomas, How to do your case study. London: Sage Publications, 2011.

[21] J. Gerring, Case Study Research - Principles and Practices. New York: Cambridge University Press, 2006.

[22] R. Yin, Case Study Research: Design and Methods, 4th Edition ed. California: Sage, 2009.

[23] R. Burns, Introduction to Research Method. London, UK: Sage Publications, 2000

[24] R. Braz, L. Scavarda, and R. Martins, "Reviewing and improving performance measurement systems: An action research," International Journal of Production Economics, vol. 133, pp. 751-760, 2011.

[25] S.-I. Su, B. Gammelgaard, and S.-L. Yang, "Logistics innovation process revisited: insights from a hospital case study," International Journal of Physical Distribution \& Logistics Management, vol. 41, pp. 577-600, 2011.

[26] D. Stengel, M. Bhandari, and B. Hanson, Statistics and Data Management: A Practical Guide for Orthopaedic Surgeons, 1 ed. Switzerland: AO Publishing, 2010.

[27] D. Baden, I. Harwood, and D. Woodward, "The effect of buyer pressures on suppliers in SMEs to demonstrate CSR practices: An added incentive or counter-productive?," European Management Journal, vol. 27, pp. 429-441, 2009. 